\section{The State Of The Prostacycline-Thromboxane System In Patients With Ischemic Heart Disease}

\author{
Khattahanova Rabiya Yuldashevna, \\ Candidate Of Medical Sciences, Senior Lecturer Of The \\ Department Of Internal Diseases No.1, \\ Fergana Branch Of The Tashkent Medical Academy, \\ Fergana City, The Republic Of Uzbekistan
}

\author{
G OPEn ACCESS \\ The American Journal of \\ Medical Sciences And \\ Pharmaceutical \\ Research \\ JULY 2020 \\ Page No.: 38-42 \\ Volume-II Issue-VII \\ PUBLISHED: 30 JULY 2020 \\ www.usajournalshub.com/inde \\ x.php/TAJMSPR \\ Copyright: Original content \\ from this work may be used \\ under the terms of the \\ Creative Commons Attribution \\ 4.0 licence.
}

\begin{abstract}
The aim of the work was to study the state of the prostacyclin-thromboxane system (PTS) and platelet functions in patients with coronary heart disease (CHD). 86 patients with CHD were examined. The state of PTS was examined by the content of prostacyclin and thromboxane in the blood, determined by radioimmunological method. Platelet hemostasis was studied by the aggregation properties of platelets and the platelet release reaction for $\beta$-thromboglobulin determined by radio immunological method. In patients with IHD, pronounced violations of the prostacyclin-thromboxane balance in the direction of the predominance of thromboxane and an increase in the functional activity of platelets, expressed in increased aggregation and platelet release reaction. In patients with IHD with post infarction cardio sclerosis, the level of prostacyclin in the blood significantly exceeds the level in patients without myocardial infarction. The content of prostacyclin and thromboxane in the blood does not differ in patients with stable angina of functional classes III and IY.
\end{abstract}

Keywords: prostacyclin-thromboxane system, platelet aggregation, ischemic heart disease, $\beta$-thromboglobulin, myocardial infarction, prostacyclin, thromboxane.

\title{
Introduction
}

As you know, the basis of coronary heart disease is an increased tendency to thrombosis and vascular spasms. These processes are under the regulatory influence of many 
systems, including prostacyclin-thromboxane $[2 ; 6 ; 7]$. Prostacyclin is a powerful antiaggregatory and coronary-extending action. Thromboxane, on the contrary, is a stimulator of platelet aggregation and a vasoconstrictor $[3 ; 4 ; 7]$ the quantitative ratio of these hormones determines the rheological properties of blood and the volume of blood flow in the myocardium. Prostacyclin-thromboxane system has a significant impact on General and regional hemodynamics, heart activity and the state of platelet-vascular hemostasis $[2,6,7]$.

In recent years, prostacyclin and thromboxane have been the objects of intensive research to determine their role in the pathogenesis of CHD $[4,6,7]$. Numerous clinical studies have revealed an increase in the functional activity of platelets in patients with IHD $[3,4,7]$. Disorders of platelet function in patients with CHD, apparently, are associated with an imbalance in the state of PTSD, so the study of the state of this system becomes important. The purpose of our work was to study the state of PTSD and platelet functions in patients with $\mathrm{CHD}$.

\section{Material And Methods}

The work is based on the survey data of 86 patients with CHD, angina of tension and rest, who were treated at the Scientific center of surgery of the Russian Academy of medical Sciences. All the examined patients were male. The age of patients is 30-65 years. The average age is $50.64 \pm 0.94$ years. According to the severity of the disease, all patients are assigned to the III and IV functional class (FC) according to the new York classification of cardiologists. All the examined patients received basic medical therapy with antiplatelet agents, nitroglycerine-type drugs, beta - blockers, statins, and antiarrhythmic drugs, cardiac glycosides, and potassium medications. A set of methods was used to examine patients. It included: the study of PTSD, platelet hemostasis, Central and peripheral hemodynamics.

The state of PTS was assessed by the content in venous blood plasma of stable metabolites prostacyclin and thromboxane-6-keto-Pgf1a and Thb2, determined by radioimmunological method. Platelet hemostasis was studied by the aggregation properties of platelets and the platelet release reaction for $\beta$-thromboglobulin determined by radioimmunological method. Platelet aggregation properties were determined using the V. R. Born method using the ELVI - 840 device.

\section{Results And Discussion}

The content of prostacyclin and thromboxane metabolites in blood plasma and indicators that characterize the functional activity of platelets in patients with coronary heart disease and in healthy people are presented in table 1.

\section{Table 1}

The content of prostacyclin and thromboxane and indicators of function of platelets in healthy people and patients with coronary artery disease 
THE AMERICAN JOURNAL OF MEDICAL SCIENCES AND PHARMACEUTICAL RESEARCH

ISSN (e): 2689-1026

DOI: https://doi.org/10.37547/TAJMSPR/Volume02Issue07-06

\begin{tabular}{|l|l|l|}
\hline \multirow{2}{*}{ Studied indicators } & \multicolumn{2}{|l|}{ Study group } \\
\cline { 2 - 3 } & $\begin{array}{l}\text { CHD patients ( n - } \\
\mathbf{8 6})\end{array}$ & Healthy (n-44) \\
\hline $\begin{array}{l}\text { Prostacyclin } \\
\text { (PG/ml) }\end{array}$ & $391.14 \pm 59.28$ & $189.72 \pm 9.75^{*}$ \\
\hline $\begin{array}{l}\text { Tromboxan } \\
\text { (PG/ml) }\end{array}$ & $300.77 \pm 38.84$ & $80.56 \pm 2.94^{*}$ \\
\hline Prostacyclin/thromboxane & $1.19 \pm 0.12$ & $2.35 \pm 0.08^{*}$ \\
\hline $\begin{array}{l}\text { Platelet count } \\
\text { (thousand/mm) }\end{array}$ & $290.7 \pm 15.88$ & $275.0 \pm 12.7 *$ \\
\hline $\begin{array}{l}\text { Platelet aggregation rate } \\
\text { (mm/min) }\end{array}$ & $18.91 \pm 0.48$ & $15.33 \pm 0.62^{*}$ \\
\hline$\beta$-thromboglobulin & $71.73 \pm 11.13$ & $42.55 \pm 7.85^{* *}$ \\
\hline
\end{tabular}

$*-\mathrm{P}<0.01, * *-\mathrm{P}<0.05$-reliability of the difference between indicators between groups

As can be seen from the presented data, all examined patients with CHD have marked changes in the state of PTSD. The content of thromboxane in blood plasma exceeds its level in healthy individuals by 3.7 times, while the content of prostacyclin was increased by 2 times. As a result, in patients with IHD, the ratio between the levels of thromboxane and prostacyclin significantly shifts towards the predominance of thromboxane, which, probably, along with other factors, can contribute to an increase in the functional activity of platelets, vasoconstriction of coronary vessels and determines the clinical picture of IHD.

When studying the functional properties of platelets, we found a significant increase in the rate of platelet aggregation $(P<0.01)$ in patients with IHD compared to the same indicator in healthy people.

In all the examined patients with CHD, we found an increase in the level of $\beta$ thromboglobulin in the blood $(P<0.05)$, which indicates an increased blood pressureplatelet regressions and their release reactions.

Thus, in patients with coronary artery disease is an imbalance of prostacyclin and thromboxane in the prevalence of thromboxane and increased functional activity of platelets, reflected in the increase of $\beta$ - thromboglobulin in the blood and increase the speed of platelet aggregation.

In our work, we analyzed the state of PTSD in patients with CHD, depending on the type of disease and the presence of a history of myocardial infarction.

We found that in patients with a previous myocardial infarction, the content of plasma prostacyclin is 1.5 times higher than in patients without a myocardial infarction and 2.5 times higher than in healthy people. The content of prostacyclin in the blood of patients without myocardial infarction and in healthy people does not significantly differ.

The level of thromboxane in blood plasma in patients with a previous myocardial infarction is 4 times, and in patients without a myocardial infarction is 3.5 times higher than its content in healthy individuals, but there are no significant differences between groups of patients depending on the previous myocardial infarction.

The ratio of prostacyclin/thromboxane in patients with a previous myocardial infarction is significantly higher than in patients without a myocardial infarction, but significantly lower $(P<0.01)$ than in healthy people. In patients without myocardial 
infarction, the ratio between prostacyclin and thromboxane levels is significantly lower $(P<0.01)$ than in healthy people and has a shift towards the predominance of thromboxane.

The increased level of prostacyclin detected by us in patients with myocardial infarction probably reflects the patient's frequency and intensity of stimuli for prostacyclin synthesis.

There was no significant difference in the number of platelets, their aggregation rate, and the content of $\beta$-thromboglobulin in patients with and without myocardial infarction.

We found no significant differences in the content of prostacyclin and thromboxane between patients of functional classes III and IY. Indicators that characterize the functional activity of platelets in patients of functional classes III and IY did not significantly differ from each other.

According to the results of our study, we found not an absolute, but a relative decrease in the level of prostacyclin in the body. In response to the increased level of thromboxane in patients with IHD, the synthesis of prostacyclin, a physiological antagonist of thromboxane, compensatory increases. However, due to the reduced ability of atherosclerotic vessels to synthesize prostacyclin, its production, in our opinion, is insufficient to counteract the increased level of thromboxane.

As a result, in the patients we examined, the ratio between prostacyclin and thromboxane has a shift towards the predominance of thromboxane. An increase in the level of thromboxane may be a decisive factor responsible for the state of coronary blood flow and tone of the coronary arteries and contributes not only to the occurrence, but also to the deepening of the process of myocardial ischemia.

The results of our study confirm the literature data on increased platelet activity in patients with IHD. All the patients we examined showed an increase in the rate of platelet aggregation and an increase in the level of $\beta$-thromboglobulin in blood plasma, which indicates increased adhesion and aggregation of platelets and their release reaction.

One of the factors contributing to an increase in platelet aggregation and their release reaction in patients with IHD is atherosclerotic changes in the arterial wall. When platelets come into contact with atherosclerotic plaques of vessels, their mechanical damage occurs, on the one hand, adhesion, on the other-aggregation. In a study by J. D. Folts et al. it is proved that the turbulent blood flow that occurs in the areas of atherosclerotic plaques can play a significant role in thrombo-formation by causing platelet aggregation. As a result of platelet adhesion and aggregation, $\beta$ - thrombo-globulin and thromboxane are released into the blood, stimulating further platelet aggregation.

When analyzing the state of PTSD depending on the history of myocardial infarction, we found that patients with a previous myocardial infarction have higher levels of prostacyclin in the blood compared to patients without a heart attack. The reason for this phenomenon is not clear. Probably, CHD should be considered as a dynamic process with a change of causes and effects. Factors that are important at the stages of onset and development of the disease may lose their significance as it progresses and give way to new ones. The appearance of stenosing coronary atherosclerosis, more often observed in patients with postinfarction cardiosclerosis, is apparently accompanied by a relative weakening of the role of functional factors and the mobilization of the protective and 
adaptive mechanism, which is expressed in a compensatory increase in prostacyclin synthesis.

Thus, in patients with CHD, there is a violation of prostacyclin-thromboxane balance and as a reflection of this process, an increase in platelet activity. Therefore, the need to restore a normal balance between prostacyclin and thromboxane as one of the conditions for successful treatment and prevention of IHD is obvious.

\section{Conclusions}

1. In patients with IHD, there are pronounced violations of prostacyclin-thromboxane balance in the direction of the predominance of thromboxane.

2. In patients with $\mathrm{CHD}$, an increase in the functional activity of platelets was detected, which is expressed in increased aggregation and release reaction

3. In patients with IHD with postinfarction cardiosclerosis, the blood content of prostacyclin significantly exceeds its level in patients without myocardial infarction.

4. The content of prostacyclin and thromboxane in the blood does not differ in patients with stable angina of functional classes III and IY.

\section{References}

1. Adaptation, stress and prevention. 2001. pp. 215-226.

2. Alekseeva N. P., Makoeva L. D. Influence of exogenous prostaglandins on the cardiovascular system. // Medicine. 2005. pp. 96-99.

3. Baluda V. P. the Role of PG, Tha2 and PGI2 in regulating the aggregation process and platelet release reaction in normal and pathological conditions. // Pathological physiology and experimental therapy. 2004. issue 4. pp. 80-85.

4. Baluda V. P. Platelet-vascular link of the hemostasis system in patients with ischemic heart disease under conditions of emotional stress. // Dissertation ... candidate of medical Sciences. 1994.

5. Biological active substances in General anesthesia and intensive care. // Himmelfarb G. N., Gerasimov N. M. Tashkent, Medicine, 2000, p. 192.

6. Boroyan R. G. Cardiovascular effects of prostaglandins and data on the mechanisms of their action. // Dissertation ... doctor of medical Sciences. 2004

7. Ismailov sh. I., Valdman A.V. the Role of prostacyclin and thromboxane in the cardiovascular system. // Cardiology. 2001. No. 3, p. 111-116.

8. Chelly J. E., Fricot A.M, Garoia A. Hemodinamics effects of prostaciclin infusion after coronary bypass surgery. // Clinlcal pharmacology of prostaciclin. Edltors P. G. Lewis , J. O.Grady, Raven press, 2006 , p. 209-214. 